\title{
Structured Intervention as a Tool to Shift Views of Parent- Professional Partnerships: Impact on Attitudes Toward the IEP
}

\author{
Mariana Mereoiu \\ Bowling Green State University \\ Sara Abercrombie \\ Northern Arizona University \\ Mary M. Murray \\ Bowling Green State University
}

\begin{abstract}
The Individualized Education Program (IEP) is the roadmap that helps educators and families drive the education of students with disabilities, improve outcomes, and fulfill each child's potential. However, the IEP can be challenging due to the large number and diversity of stakeholders, dynamics and culture of collaboration, and the complex procedures guiding the referral, evaluation, and placement. This study describes changes in attitudes toward the IEP reported by special educators and parents participating in a statewide six-month collaborative training model. Preand post-test data analysis indicates an interaction effect on overall attitude toward the IEP, with parents' ratings of the value of the IEP decreasing at the end of the training and teachers' ratings increasing. Moreover, special educators' significantly higher ratings of the value of team planning for the IEP indicate enduring pre-and post-intervention differences. These findings have implications for school districts and agencies providing professional development to improve collaboration in IEPS.
\end{abstract}

Established through the Individuals with Disabilities Education Improvement Act of 2004 (IDEA), the Individualized Education Program (IEP) represents the fundamental guiding tool in providing special education services to students with disabilities in the United 
States (Ruble, McGrew, Dalrymple, \& Jung, 2010). Developing IEPs is a team-based process and requires that individuals who are familiar with (or work closely with) students be included in the IEP process (Patti, 2016). These individuals often include general education teachers, parents, special educators, school psychologists, therapists, administrators and other related service providers, and school professionals. When appropriate, students are also included in the IEP process. Ideally, IEPs should be viewed as a tool that facilitates communication and collaboration among the IEP team members (Williams-Diehm, Brandes, Chesnut, \& Haring, 2014).

When developing IEPs, team members are tasked with identifying each student's current level of performance, measurable annual goals and ways to measure progress toward these goals, special education services, related and supplementary aids and services, and nature of least restrictive environment. Team members also are responsible for periodically reviewing IEPs and revising them based on the progress and anticipated needs of each student (IDEA C.F.R. $34 \S 300.324(\mathrm{~b})$ ). Despite the targeted precision with which IEPs are ideally created, the design and delivery of special education services often turns out to be a complex process due to multiple factors: (a) the many stakeholders invested in the process and the wide variety of cultural and linguistic backgrounds they represent, (b) the dynamics of power and interactions in the collaboration process, and (c) the multitude of procedures and compliance requirements specific to each of the IEP components.

\section{The IEP Process: Issues and Experiences of Families and Educators}

Stepping into the IEP process, both professionals and parents find themselves in a context in which collaboration is essential in order to achieve positive outcomes. More specifically, understanding the concept of collaboration and what it entails within the special education arena is critically important in establishing and sustaining collaborative partnerships. Collaborative skills may include the ability to establish rapport, to communicate effectively, to share in the decision-making process, and to recognize the expertise of each IEP team member (Diliberto \& Brewer, 2012; Turnbull, Turnbull, Erwin, Soodak, \& Shogren, 2015). However, participants in the IEP start this journey with a variety of prior experiences, as well as with differences in the knowledge and skills required to conduct successful IEP meetings.

Typically, special education teachers provide the most extensive input in IEP meetings. In a three-year study examining the perceptions of more than 1,600 participants, Martin, Marshall, and Sale (2004) indicated that special education teachers provided the most input in IEP meetings about students' strengths, needs, and interests. In addition, special education teachers recorded the highest scores in their self-reported (a) level of understanding about tasks they needed to complete in IEP meetings, (b) level of engagement in decision-making processes, and (c) ability to identify next steps (Martin, Marshall, \& Sale, 2004). However, general education teachers and special education teachers alike also have reported that they do not feel fully prepared to address the needs of all students with disabilities (Coleman, Cramer, Park, \& Bell, 2015; Westling, 2010). In their study investigating collaborative planning among general education instructors and special education instructors, Carter, Prater, Jackson, and Marchant (2009) found that 
sometimes teachers do not possess the skills to properly identify problems that need to be addressed, nor do they possess adequate communication skills to negotiate the differences in perspectives regarding these problems. Moreover, some teachers avoid discussing differences in opinions about students' needs and therefore fail to engage in conversations that might clarify the nature of these needs as well as the necessary planning and delivery of services (Carter et al., 2009).

In addition to the challenges faced by educators in working with special education students, parents also have reported that the IEP process can be challenging. In their study investigating parents' collaboration with schools, Tucker and Schwartz (2013) found that some parents' ideas were not included in the educational planning process because the IEPs were created without communicating with parents. By contrast, in the same study and similar to other studies, parents identified as facilitators in collaboration: IEP meetings attendance, prompt return of phone calls, and resource sharing (Tucker \& Schwartz, 2013; see also Shelden, Angell, Stoner, \& Roseland, 2010). In fact, communication between schools and parents or family members has been a prevalent theme in the research literature investigating collaboration in special education (Friend \& Cook, 2013; Turnbull et al., 2015). Parents have reported feeling frustrated, isolated, excluded, and disempowered in the IEP process due to a lack of communication and weak partnerships with schools (Hess, Molina, \& Kozleski, 2006).

One specific difficulty in the area of communication is the use of professional jargon, which can be particularly challenging for parents who are not familiar with special education processes. In a study conducted with fathers of students with disabilities, the participants described the IEP meetings as "overwhelming" because of professional jargon, the complexity of IEP procedures, and the intensity of emotions family members often experience (Mueller \& Buckley, 2014). The IEP process can be overwhelming for parents who have not fully processed the meaning and implications of their child's diagnosis, while educators and school specialists are often already focusing on developing a plan of service, contributing to an even greater divide between parents and professionals. In the struggle to meet the demands of the IEP as a standardized process with specific proceedings, the needs of the family are often overlooked (Hess et al., 2006); and parents' trust in the IEP process is sometimes undermined when professionals fail to implement IEP requirements and recommendations for accommodations (Angell, Stoner, \& Shelden, 2009).

In addition to collaboration and communication challenges, some of the complexity of the IEP process derives from the number of participants involved and the difficulties negotiating multiple perspectives and experiences. Another source of difficulty in collaboration is the discrepancy between (a) the increase in cultural and linguistic diversity among children and families and (b) the lack of training in culturally sensitive practices among teachers (Tisdell, Taylor, \& Forté, 2013). The variety of needs among special education students, the complexity of procedures involved with the IEP process, and the knowledge and skills required for participation can also pose substantial challenges for general education teachers as well as for special education teachers serving children with disabilities. Special education teachers and other school professionals involved in the IEP need to develop skills to establish rapport with families, who often present unique circumstances and strong emotions; and they need be able to create 
genuine opportunities for collaboration throughout the IEP process (Van Haren \& Fiedler, 2008).

\section{Theoretical Framework}

The theoretical framework best suited for this study is transformative learning. According to Mezirow (1997), a transformative learning approach results in changing the learner's frame of reference. More specifically, in a transformative learning environment, learners are faced with a disorienting dilemma that challenges their prior knowledge, experiences, and views. The starting premise is that learning is shaped and delimited by the learner's frames of references (Mezirow, 1994). However, information and concepts that do not fit within prior frames of reference typically trigger resistance. As learners continue to experience the need to make meaning of new experiences, they engage in a process of critical self-reflection regarding their assumptions (Kitchenham, 2008; Mezirow, 1998a, 1998b). By examining the grounds supporting their own assumptions and the new information they encounter, learners must negotiate and create changes in their meaning structures in order to achieve a rational discourse and, ultimately, a new understanding of the context subject to analysis (Mezirow, 1994). Parents who participate in special education services for their children enter this process with prior experiences that may or may not align with the current context. At the same time, as professionals enter the special education process and collaborate with families, they also rely on their prior frames of references, which typically are based on previous collaboration experiences and their training.

In this current study, special education professionals were paired with parents of children with disabilities for a period of six months. A primary goal of this collaboration was to create sustainable changes in the ways school districts collaborate with parents of students with disabilities. School districts who volunteered to participate in this project identified collaboration with families as an area in need of improvement. The training employed a train-the-trainer model through which parents and teachers teamed in a learning community. The goal of the parents and teachers was to learn and practice strategies for identifying issues that inhibit collaboration and for developing ways to address them. The parents and the teachers then shared the training model with special educators and parents in their own school districts. In this train-the-trainer model the goal of the teachers was to determine how best to involve parents and caregivers in partnerships with schools, whereas the goal of the parents was to identify and exercise the most effective ways to share their children's stories and to collaborate with educators. Part of this process required special education teachers to engage in conversations with parents and together determine how to promote parent partnerships in the districts. Various modules and activities were provided throughout the training, but they served primarily as a framework. Each parent-teacher team was required to develop a strategic plan for continuing to implement the partnership principles and strategies of this training model in their school districts. They developed short-term and long-term goals for their districts. Some teams identified opportunities for parents to make meaningful contributions to their districts, while other teams developed ways to help empower parents through the IEP process. Other teams identified strategies for promoting effective communication between special education teachers and parents. Some teams decided to 
implement their strategies in a single building within a district, while other teams decided to implement their strategies within the entire district. Parents as well as professionals entered these partnerships with prior knowledge and frames of reference that shaped their experience in this professional development opportunity. However, using one's own frame of reference might in fact inhibit an accurate understanding of others' experiences and perspective. Therefore, a transformative learning experience was needed to identify changes at an individual level, which in turn helped parents and educators both gain new insight into the special education collaboration processes. This transformative learning experience was created through a learning community in which parents and educators were tasked to identify meaningful goals and strategies tailored to the needs of their districts. The study aimed to explore the influence of a structured family-professional partnership intervention on perceptions of the IEP process. More specifically, this study investigated the following research question: What is the influence of a structured family-professional partnership intervention on the views toward the IEP? To examine the influence of the intervention, the study targeted the following specific areas: attitudes toward the IEP's value for instructional planning, curriculum planning, individualized instruction, team planning, and overall attitude toward IEP.

\section{Methods}

This section presents findings based on data that were collected during a larger project. Data were collected before the professional development intervention described above and at the completion of it.

\section{Context and Purpose of the Study}

The special education division of the state agency in a midwestern U.S. state (in collaboration with researchers from a higher education institution and other agencies serving children with disabilities) designed and implemented a training model focused on preparing special educators and families to effectively collaborate and thereby support student outcomes. The training model was supported by federal funds awarded to the agency for its statewide improvement process. Throughout this training, special education teachers and parents of children with disabilities from 16 school districts were paired together and asked to participate in a six-month collaborative professional development program targeting collaboration in special education. The teams participated in alternate face-to-face and online training sessions that focused on concepts and strategies designed to enhance collaboration. These included strategies for effective communication, equality in partnerships, decision-making principles regarding the education of students with disabilities, respect, trust, advocacy, and principles of collaborative partnerships. We identified active, meaningful participation and empowerment of parents in the IEP process as concerns to be addressed throughout the training. Every training module included strategies to help support parents during the IEP process. For example, the module on communication not only provided information about how to communicate effectively with parents in general, but it also included even more specific strategies to help foster effective communication during the IEP process. The training model employed a train-the-trainer approach, which means that the participants had to identify 
collaboration training goals specific to their own school districts, identify plans to deliver the training to teachers and parents in their districts, implement the training, and report on the outcomes. Both in face-to-face meetings and online sessions participants had opportunities to report and reflect on the progress of their implementation, successes and challenges they faced, and ways in which they personalized the recommended practices to fit the needs of their districts. The purpose of this study was to explore changes in views toward the IEP process among special education teachers and parents in response to their participation in this collaborative training experience.

\section{Participants and Design}

Parents and professionals representing a variety of positions from each of the 16 districts were invited to participate in the study. Due to attrition during the training and due to the fact that some districts sponsored more than one parent or professional participant, a total of 21 professional participants and 18 parent participants were invited to complete questionnaires. Because the purpose of the study was to measure changes in attitude as a result of the intervention, only participants who completed the questionnaire before and after the intervention were included in the current analysis. This reduced the total number of participants to 12 parent participants and 15 professional participants. Table 1 summarizes the distribution of gender, age, and ethnicity in the two groups.

Table 1.

Frequencies of Gender, Age, and Ethnicity Categories of Family and Professional Study Participants

\begin{tabular}{lcc}
\hline & Family $(\boldsymbol{n}=\mathbf{1 2})$ & $\begin{array}{c}\text { Professional } \\
(\boldsymbol{n}=\mathbf{1 5})\end{array}$ \\
\hline Gender & 12 & 12 \\
Female & 0 & 3 \\
Male & & \\
Age & 3 & 0 \\
$26-30$ & 1 & 1 \\
$31-35$ & 2 & 1 \\
$36-40$ & 5 & 5 \\
$41-50$ & 1 & 3 \\
$51-55$ & 0 & 5 \\
$56+$ & & \\
Ethnicity & 1 & 0 \\
African American & 10 & 15 \\
Caucasian/White & 1 & 0 \\
Hispanic/Latina & & \\
\hline
\end{tabular}

Of the 15 professional participants, 3 reported some personal experience with children or individuals with disabilities outside of their profession (e.g., as a family member or friend), and 7 of the 12 parent participants reported some professional experience in education (e.g., working in schools as teachers, consultants, etc.). 


\section{Instrumentation}

Demographics survey. All participants were asked to complete a demographic questionnaire that solicited the following information: gender, age, ethnicity, role in the training program (i.e., family member or professional). Parent participants were also asked whether they had any prior professional experience working with children with disabilities and their families, and professional participants were asked whether they had any prior personal experience with children with disabilities and their families (e.g., as a family member or friend of an individual with a disability).

Attitudes Toward the IEP survey. An adapted version of the Attitudes Toward the IEP questionnaire (ATIEP; Ryan \& Rucker, 1991) was used to measure the attitudes of parents and special education professionals toward the IEP on five factors. The ATIEP questionnaire was first developed as a 25 -item Likert scale instrument $(1=$ strongly disagree; 5 = strongly agree) to measure teacher attitudes about the value of the IEP in various aspects of their work. The initial validation study was conducted with a sample of 207 special education teachers from the state of Rhode Island in the United States. In their study, Ryan and Rucker first developed a 40-item instrument based on teacher attitudes toward the IEP reported in the research literature. These 40 items were then reviewed and edited by five content experts; as a result, 6 items were rewritten and 2 were omitted. The 38 remaining items were then tested with a sample of special education teachers. Principal component analysis with an oblique rotation was conducted, which resulted in the final 25-item version of the instrument. The instrument includes the following five scales: (a) Value for Instructional Planning, (b) Curriculum Planning, (c) Value for Individualized Instruction, (d) Team Planning, and (e) Overall Attitude. The authors reported Cronbach's alpha internal consistency for each factor as follows: Value for Instructional Planning, 0.88; Curriculum Planning, 0.66; Value for Individual Instruction, 0.77; Team Planning, 0.70; Overall Attitude, 0.64 (Ryan \& Rucker, 1991).

We made several small changes to the original ATIEP questionnaire to tailor it to the current study. For the parent participant questionnaire, we adapted the ATIEP by replacing references to "my students" with the term "my child"; however, for the professional participant questionnaire, we retained the original wording. In addition, two of the original items from the Curriculum Planning factor were omitted from the parent and teacher version of the questionnaire because they were inappropriate for parents and we planned analysis to directly compare survey results from the parents and teachers. Following are the two omitted items: Choosing IEP goals and objectives from lists helps me to systematically sequence my instructional objectives; and Using lists of IEP goals and objectives would give me more time for teaching. One additional item was omitted from the questionnaire since it was not inclusive of the continuum of services available in the U.S. state in which the study took place: IEP goals and objectives of students in the same self-contained classroom do not differ. Because the primary goal of the intervention was to help build partnerships between parents and professionals across the instructional environment, we deemed all the other items and questionnaire factors relevant to both parents and professionals. These modifications resulted in two parallel versions of the survey-one for parents and one for professionals (see Table 2 for the parent version). We did not have enough statistical power to conduct our own factor validation; therefore, we relied on the factors 
identified by Ryan and Rucker (1991) for our analyses. Items were averaged by each factor, resulting in an average score on each factor for each participant.

Table 2.

\section{ATIEP Survey Items by Factor (Parent Version)}

\begin{tabular}{|c|c|}
\hline Factor & Items \\
\hline \multirow{8}{*}{$\begin{array}{l}\text { Value for } \\
\text { Instructional } \\
\text { Planning }\end{array}$} & Once the IEP is developed I don't look at it again. * \\
\hline & The IEP reflects the educational program provided. \\
\hline & I feel I am a better parent because I have the IEP to help me support my child. \\
\hline & The IEP improves the quality of education for students with disabilities. \\
\hline & The time spent on developing the IEP does not justify its worth. ${ }^{*}$ \\
\hline & IEP goals and objectives provide a curriculum for my child. \\
\hline & The IEP helps the teacher organize and structure his/her teaching better. \\
\hline & The IEP goals and objectives are used to plan instructional activities. \\
\hline \multirow[t]{2}{*}{$\begin{array}{l}\text { Curriculum } \\
\text { Planning }\end{array}$} & $\begin{array}{l}\text { Curriculum experts should help school systems develop lists of goals and } \\
\text { objectives. }\end{array}$ \\
\hline & $\begin{array}{l}\text { Using commercial or system developed goals and objectives cuts down on } \\
\text { time required to develop IEPs. }\end{array}$ \\
\hline \multirow{4}{*}{$\begin{array}{l}\text { Value for } \\
\text { Individualized } \\
\text { Instruction }\end{array}$} & $\begin{array}{l}\text { The IEP goals and objectives for children in the same resource program do } \\
\text { not differ.* }\end{array}$ \\
\hline & $\begin{array}{l}\text { The IEP goals and objectives of children in the same program differ in level } \\
\text { of instruction but not content. }\end{array}$ \\
\hline & Once the IEP is developed I don't look at it again. * \\
\hline & IEP goals and objectives are more program specific than child specific.* \\
\hline \multirow[t]{5}{*}{ Team Planning } & The only part of the IEP that is a team decision is placement. ${ }^{*}$ \\
\hline & $\begin{array}{l}\text { The choice of IEP goals is usually left up to the special education person } \\
\text { who is providing the service. }\end{array}$ \\
\hline & No part of the IEP is truly a team decision.* \\
\hline & $\begin{array}{l}\text { The data shared at IEP meetings helps me in developing goals and objectives } \\
\text { for my child. }\end{array}$ \\
\hline & The only part of the IEP that is a team decision is service delivery. ${ }^{*}$ \\
\hline \multirow[t]{3}{*}{ Overall Attitude } & IEPs are so valuable all children should have them. \\
\hline & The IEP serves as a tool in evaluating the child's program and services. \\
\hline & $\begin{array}{l}\text { The more times I contribute to the IEP writing process, the more helpful I } \\
\text { find the IEP. }\end{array}$ \\
\hline
\end{tabular}

*Indicates negatively worded item, reverse scored for analyses.

\section{Procedures}

The questionnaires were administered to participants twice. The first administration occurred at the beginning of the first instructional session. At this point, informed consent forms and questionnaires were administered to all participants; parents received the parent participant version of the questionnaire, and professionals received the professional 
participant version. Participants were provided approximately 30 minutes to complete the questionnaire and return it to us. The second administration occurred during the last instructional session, and questionnaires were administered in a similar fashion. All questionnaires were identified using a unique ID assigned to each participant, and the questionnaire forms themselves did not request names. The first administration and second administration questionnaires were linked using the unique ID provided to each participant.

\section{Results}

Data were analyzed employing five repeated measures ANOVAs, with one measure for each of the ATIEP factors as the dependent variable. Time was considered the between-groups variable (i.e., pre-survey as time 1 and post-survey as time 2), and role (parent or professional) was considered the between-subjects variable. The critical value for statistical tests was set at $p=.05$. Results for each analysis are reported below. Means and standard deviations for each ATIEP factor by each group are reported in Table 3.

Table 3.

Means and Standard Deviations for Parents and Professionals on All Factors of the ATIEP Survey Pre- and Post-Intervention

\begin{tabular}{lcc}
\hline Factor/Group & $\begin{array}{c}\text { Pre- } \\
\text { intervention }\end{array}$ & $\begin{array}{c}\text { Post- } \\
\text { intervention }\end{array}$ \\
\hline M (SD) & M (SD) \\
\hline $\begin{array}{l}\text { Value for Instructional Planning } \\
\quad \text { Parents }\end{array}$ & $3.79(0.53)$ & $3.65(0.61)$ \\
$\quad$ Professionals & $3.48(0.40)$ & $3.67(0.59)$ \\
Curriculum Planning & & \\
$\quad$ Parents & $2.88(0.96)$ & $3.08(0.93)$ \\
$\quad$ Professionals & $2.83(0.88)$ & $2.60(0.99)$ \\
Value for Individualized Instruction & & \\
$\quad$ Parents & $3.96(0.55)$ & $3.87(0.84)$ \\
$\quad$ Professionals & $4.01(0.69)$ & $4.14(0.57)$ \\
Team Planning & & \\
$\quad$ Parents & $4.10(0.54)$ & $4.09(0.63)$ \\
$\quad$ Professionals & $4.48(0.44)$ & $4.47(0.69)$ \\
Overall Attitude & & \\
$\quad$ Parents & $3.72(0.91)$ & $3.61(0.74)$ \\
$\quad$ Professionals & $3.24(0.97)$ & $3.96(0.63)$ \\
\hline Note: All factors measured on a Likert scale where 1 strongly disagree and \\
5 = strongly agree
\end{tabular}

For each ATIEP factor, our analysis asked, "Does a parent-professional partnership intervention change parents' and professionals' attitudes in relation to this factor," as reported in the following sections. 


\section{Value for Instructional Planning}

No time, $F(1,25)=0.072, p=0.791$, or time-by-group interaction, $F(1,25)=2.68$, $p=0.114$, was found on participants' attitudes toward the IEP's value for instructional planning. In addition, no overall difference was found between the parent group and professional group, $F(1,25)=0.641, p=0.431$. This suggests that the participants' views on the value of the IEP for instructional planning were not influenced by the intervention. In addition, parents' and teachers' views of the IEP value for instructional planning did not differ significantly.

\section{Value for Curriculum Planning}

No time, $F(1,25)=0.005, p=0.946$, or time-by-group interaction, $F(1,25)=1.435$, $p=0.242$, was found on participants' attitudes toward the IEP's value for curriculum planning. In addition, no overall difference was found between the parent group and the professional group, $F(1,25)=0.705, p=0.409$. Interestingly, of all the factors, the mean scores on this factor were lowest for both parents and professionals, suggesting that (at least descriptively) both groups reported less positive attitudes toward the IEP's value for curriculum planning than for other factors.

\section{Value for Individualized Instruction}

No time $F(1,25)=0.016, p=0.902$, or time-by-group interaction $F(1,25)=0.420$, $p=0.523$, on participants' attitudes toward the IEP's value for individualized instruction was found. In addition, no overall difference between the parent group and professional group was found $F(1,25)=0.723, p=0.403$. This suggests that parents' and teachers' views on the value of the IEP for individualized instruction did not differ significantly and that they were not significantly influenced by the intervention.

\section{Value of Team Planning}

No time, $F(1,25)=0.002, p=0.963$, or time-by-group interaction, $F(1,25)=0.001$, $p=0.98$, was found on attitudes toward value of team planning in the IEP process. However, there was a statistically significant overall difference between the groups, $F(1$, $25)=5.417, p=0.028$, indicating that both before and after the intervention, professionals rated their attitudes toward the value of team planning during IEPs significantly higher than parents do. This suggests that teachers in this study viewed the IEP as more team-based than parents did.

\section{Overall Attitude Toward the IEP}

Analysis of the data collected from these items indicated that there was no time effect, $F(1,25)=4.048, p=0.55$. However, a time-by-group interaction on Overall Attitude was found $F(1,25)=7.602, p=0.011$. This result suggests that parents and professionals were differentially affected by the intervention (see Figure 1). Interestingly, parents' ratings in the Overall Attitude factor slightly decreased during the course of the training, and professionals' ratings increased as a result of the training. It further suggests 
that before the intervention, parents' overall attitude toward the IEP were more positive than professionals' attitudes.

Figure 1.

Parent and Professional Differences on Overall Attitude Toward the IEP Pre- and Post-intervention

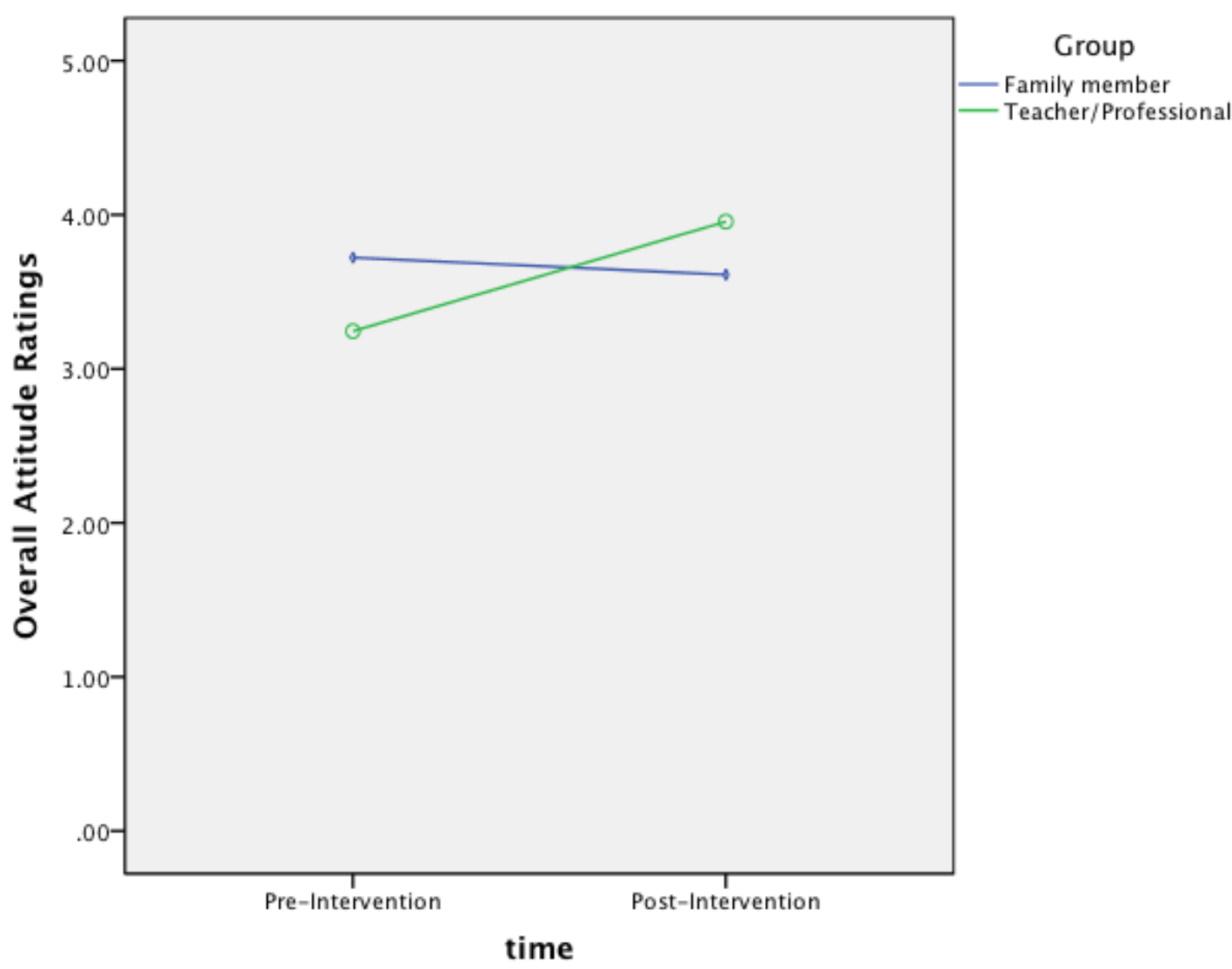

\section{Discussion}

The findings of this study indicate that parents and special education teachers view the value of the IEP process for individualized instruction in a neutral to positive way. This finding is encouraging because IEPs should ultimately provide a framework for appropriately individualized instruction, curriculum that is aligned with learning outcomes, and assessment standards that reflect these outcomes (Lynch \& Adams, 2008).

Both groups rated the items focusing on the value of the IEP process for instructional planning as medium to high, indicating that they viewed the IEP process as valuable for setting goals and establishing objectives that improve instruction and the quality of education for students with disabilities. Indeed, effective planning is fundamental in all educational processes, but it is even more important in the IEP process. When educators treat the IEP process as a critical tool and use it consistently in designing individualized 
instruction, real opportunities for improved outcomes open for students with disabilities. Considering that parents, family members, and special education teachers participating in this study believed that IEPs should lead to individualized learning goals, specialized instruction, and individual activities for students with disabilities, it is not surprising that parents of children with exceptionalities preferred individualization of goals specific to their child and did not view the use of commercial systems offering lists of goals and objectives as necessarily decreasing the time required to develop the IEPs. Identifying high quality IEP goals requires a great deal of careful consideration and therefore significant time; however, it is a task well worth considering given that these goals ultimately drive the quality of education for students with disabilities (Konrad et al., 2014). Even though electronic IEP software programs are effective tools that allow multiple service providers simultaneous access to (a) IEP documents, (b) "goal banks" often aligned with states' curriculum content standards, and (c) a management system of procedural due dates, it is still recommended that IEP members create personalized banks of goals to fit the unique needs and learning profiles of students (More \& Hart, 2013; More \& Hart Barnett, 2014). Overall, the results of teachers creating their own goal banks are encouraging because they indicate that IEPs are personalized for each student as intended: the roadmap toward appropriate education for students with disabilities (Turnbull, Turnbull, Erwin, Soodak, \& Shogren, 2015.

Compared to parents and family members, teachers were more likely to view the IEP as a team-based process. Both before and after the training, professional participants rated the value of team planning throughout the IEP process higher than did parent participants. Because the perspectives of educators are the lenses through which they frame their practice, it is highly encouraging that the professional participants viewed the processes of identifying IEP goals, placing students with disabilities, and delivering services to students with disabilities as team-based decisions. At the same time, this result is consistent with reports in the literature indicating that parents often do not view themselves as equal members of the IEP teams because of insufficient time for conferences, limited roles in decision making, and inadequate provision of meaningful opportunities to participate (Hammond, Ingalls, \& Trussell, 2008; Turnbull et al., 2015). Similar to this finding, McNulty, Prosser, and Moody (2011) found in their review of research studies including families of diverse backgrounds that parents have experienced roadblocks in the IEP team process. These roadblocks include educators and school professionals using predetermined goals and objectives to establish IEP and/or poor communication between school professionals and parents. Research studies also have indicated that IEP plans are written above the recommended readability level, which may prevent some parents from fully understanding their child's IEP (Fitzgerald \& Watkins, 2006; Lo, 2014; Pizur-Barnekow, Patrick, Rhyner, Folk, \& Anderson, 2010). The fact that parents reported lower ratings than did professionals regarding the value of IEP teams (both before and after the intervention) might have been influenced (a) by prior experiences and (b) by discrepancies created between those prior experiences and their new or enhanced understanding of the IEP process and recommended practices for IEP collaboration. More specifically, it is possible that the knowledge parents gained through the training (e.g., principles of collaborative practice during the IEP process, decisionmaking guidelines, the importance of parity, etc.) might have negatively influenced 
parent participants' views of the IEP as a team-based process. At the same time, given the complexity of the IEP process and the substantial knowledge and skill required by parents to actually participate in the process, these factors may have led the parents participating in this study to cautious in estimating the value of a team-based approach to IEP planning. As education agencies and school districts continue to improve partnerships in designing and implementing IEPs, it is critically important that they have an accurate understanding of the expectations held both by educators and parents related to team-based IEP planning. It is also critical that educational agencies help educators and families understand their role and also how the role of each IEP member might vary based on their expertise and the needs of students (Hartmann, 2016).

The results of this study also indicate that participating in this collaborative professional development opportunity for six months created positive changes in teachers' overall attitude toward IEPs. Although a variety of factors may have influenced participants' attitudes, it is also possible that the six-month training program and the opportunity to work closely with family members (e.g., working together to identify goals and objectives for the districts; learning about families' successes, challenges, expectations, and views; etc.) might have challenged educators' prior views. The training program also may have created awareness of multiple opportunities within the IEP process to improve students' education. If so, it may be precisely this exposure to information that challenges prior experiences and views, opening the door to critical reflection and reevaluation. On the other hand, parents provided a lower overall rating of the IEP process at the completion of the professional development program compared to their rating before the training. It is possible that this change was triggered by an enhanced understanding of (a) the complexity associated with the IEP process, (b) the long-term implications of this complexity, and (c) the substantial knowledge and skills required to successfully design educational services for student with disabilities. In order to further investigate differences in the views of teachers and parents, future research should focus on more closely exploring parent participation in the IEP process and implications for student outcomes.

Participation in the training did not result in significant changes in the views of special education teachers toward other aspects of the IEP process. There are several explanations for these results. First, participants in this study were highly invested in the education of children with disabilities; most of the special education teachers reported having experiences with children and individuals with disabilities at a personal level. Likewise, the parent participants volunteered to work with special education teachers throughout this training model. In addition, more than half of the parent participants reported that they had engaged in prior professional experiences with educational environments in some capacity. Therefore, it is safe to conclude (a) that participants in this study were motivated to improve their collaborative skills during the IEP process and (b) that they shared some prior knowledge about how schools and educational processes operate. Secondly, it is possible that professional participants and parent participants based their opinions about the IEP process on personal experience, and that this experience was more influential than the training. Third, it is possible that training addressing more specific areas of concern (as identified by special educators and families) might more substantially influence participants' perspectives on the IEP 
process. For instance, professional development targeting collaboration among parents and professionals or specific aspects of collaboration (e.g., collaborative efforts throughout transition points, collaborative practices during the evaluation process, etc.) in working with children with specific educational needs (e.g., children with autism spectrum disorder) might lead participants to rate the IEP aspects investigated in this study by referring to specific experiences. Moreover, while the professional development opportunity was delivered in within a context of a special education environment, it is possible that a small-group format might be more effective because it would provide multiple opportunities for practice, for obtaining clarification, and for individualized feedback (Kretlow \& Bartholomew, 2010). For some factors of the questionnaire, including Value for Individualized Instruction, the mean scores for both groups were quite high (e.g., within a 3.48 to 4.48 range), indicating that both groups already held positive opinions about the value of the IEP in the questionnaire factors Team Planning, Instructional Planning, and Overall Attitude . Finally, the instrument we used might not have been sensitive enough to detect and measure all the changes that the participants experienced as a result of the training, or we may have observed a ceiling effect.

The knowledge base of IEP team members, the range of their experiences, and the number of those who view the IEP process as a critical tool for guiding the education of students with disabilities have increased substantially during the past decades. Research studies investigating the perceptions of parents and caregivers regarding practices employed by professionals and school districts has provided teacher educators and practitioners opportunities to make meaningful changes toward collaboration within the IEP process. Clearly, given the wide variety of professionals present in IEP meetings, participants in this process must collectively and actively support families in understanding (a) roles and responsibilities of all stakeholders, (b) terms and procedures utilized, and (c) strategies for participating in the team-based process throughout the prereferral, referral, evaluation, and service planning processes as well as in the placement of students. Equally important, teacher education and professional development agents must be intentional in their efforts to understand special educators' needs to establish and sustain partnerships with families as well as strategies for eliciting and using parent input throughout the IEP process.

\section{Limitations}

This study explored changes in attitudes toward the IEP process influenced by participation in a six-month collaborative professional development opportunity focusing on partnerships between special educators and families of children with disabilities. The results of this study contribute to an understanding of the role of professional development and parent-professional partnerships within the IEP process. However, several limitations were encountered during this research. First, the results of this study should be carefully considered before generalizing them to a larger population due to the small sample of participants. In addition, not all parents and professionals who participated in this study completed the questionnaire, and the parents and professionals involved in the training were self-selected volunteers. Furthermore, one issue that stood out to the research team was a lack of ethnic and gender diversity both among parent 
participants and professional participants. Therefore, we cannot assume that this sample is representative of the greater population of families and professionals.

\section{Future Research Directions}

The current study contributes to the literature on the views of special education teachers and parents about the value of the IEP as a tool for instructional and curriculum planning, individualized instruction, team planning, and collaborative opportunities. However, future research investigating stakeholders' views about the IEP as a tool to improve education (and factors that influence these views) must examine more deeply the actual experiences and strategies implemented by participants. Future research exploring the effects of collaborative professional development needs to directly examine whether and how these opportunities can influence significant changes in the perspectives and behaviors of participants. Longitudinal studies employing repeated measures that target changes in views and observations of IEP meetings would contribute substantially in filling the gaps in the literature on this topic. Moreover, research based on a more representative sample of the full spectrum of parents of students with disabilities would provide the opportunity to generalize results to larger populations. It would also be valuable to explore the collaborative process throughout each stage of the special education process, particularly the evaluation and IEP design of services and placement of students with disabilities. Parents usually possess critical information that can provide insight into the comprehensive evaluation as well as into service delivery. Although the body of knowledge about recommended collaboration practices has been growing, it is important to understand the best way to help educators support families in ways that allow parents and caregivers to feel they are equal team members. Perhaps more effective professional development opportunities should embed components that allow parents and teachers or school professionals specific time and space to process and reflect on collaborative practices in homogenous groups, with the possibility of bringing back to the larger teams information about issues that are representative specifically for parents and teachers. Moreover, future research should seek to understand effective collaborative practices aimed at helping families in response to the unique needs of their children. Finally, given the wide variety of professionals participating in the IEP process, it is crucial to explore how professional development opportunities meant to improve the collaboration processes in the special education environment can be designed to include other members of the IEP process, such as school psychologists, therapists, speech language pathologists, behavioral and reading specialists, administrators, and other school professionals.

\section{References}

Angell, M. E., Stoner, J. B., \& Shelden, D. L. (2009). Trust in education professionals: Perspectives of mothers of children with disabilities. Remedial and Special Education, 30(3), 160-176. doi: $10.1177 / 0741932508315648$

Carter, N., Prater, M. A., Jackson, A., \& Marchant, M. (2009). Educators' perceptions of collaborative planning processes for students with disabilities. Preventing School Failure, 54(1), 60-70.

Coleman, M. B., Cramer, E. S., Park, Y., \& Bell, S. M. (2015). Art educators' use of adaptations, assistive technology, and special education supports for students with physical, visual, severe and multiple disabilities. Journal of Developmental and Physical Disabilities, 27(5), 637660. doi:10.1007/s10882-015-9440-6 
Diliberto, J. A., \& Brewer, D. (2012). Six tips for successful IEP meetings. TEACHING Exceptional Children, 44(4), 30-37.

Fitzgerald, J., \& Watkins, M. W. (2006). Parents' rights in special education: The readability of procedural safeguards. Exceptional Children, 72, 497-510.

Friend, M. P., \& Cook, L. (2013). Interactions: Collaboration skills for school professionals (7th ed.). Boston, MA: Pearson.

Hammond, H., Ingalls, L., \& Trussell, R. P. (2008). Family members' involvement in the initial Individual Education Program (IEP) meeting and the IEP process: Perceptions and reactions. International Journal about Parents in Education, 2, 35-48.

Hartmann, E. S. (2016). Understanding the everyday practice of Individualized Education Program team members. Journal of Educational and Psychological Consultation, 26, 1-24.

Hess, R. S., Molina, A. M. , \& Kozleski, E. B. (2006). Until somebody hears me: Parent voice and advocacy in special educational decision making. British Journal of Special Education, 33(3), $148-157$.

Individuals with Disabilities Education Improvement Act Regulations, 34 C.F.R. §300.324(b) (2006).

Konrad, M., Keesey, S., Ressa, V. A., Alexeeff, M., Chan, P. E., \& Peters, M. T. (2014). Setting clear learning targets to guide instruction for all students. Intervention in School and Clinic, 50(2), $76-85$.

Kretlow, A. G., \& Bartholomew, C. C. (2010). Using coaching to improve the fidelity of evidencebased practices: A review of studies. Teacher Education and Special Education, 33(4), 279299. doi:10.1177/0888406410371643

Lynch, S., \& Adams, P. (2008). Developing standards-based Individualized Education Program objectives for students with significant needs. Teaching Exceptional Children, 40(3), 36-39.

Lo, L. (2014). Readability of Individualized Education Programs. Preventing School Failure, 58(2), 96-102.

McNulty, C., Prosser, T., \& Moody, A. K. (2011). Family connections: Empowering families to be collaborative participants in IEP meetings. Childhood Education, 87(2), 129-130. doi:10.1080/00094056.2011.10521459

Mezirow, J. (1994). Understanding transformation theory. Adult Education Quarterly, 44(4), 222-232.

Mezirow, J. (1997). Transformative learning: Theory to practice. New Directions for Adult and Continuing Education, 74, 5-12.

Mezirow, J. (1998a). Cognitive processes: Contemporary paradigm of learning. In P. Sutherland (Ed.), Adult learning: A reader (pp. 2-13). Stirling, VA: Kogan Page.

Mezirow, J. (1998b). On critical reflection. Adult Learning Quarterly, 48(3), 185-198.

More, C. M., \& Hart, J. E. (2013). Maximizing the use of electronic individualized education program software. Teaching Exceptional Children, 45(6), 24-29.

More, C. M., \& Hart Barnett, J. E. (2014). Developing individualized IEP goals in the age of technology: Quality challenges and solutions. Preventing School Failure, 58(2), 103-109.

Mueller, T. G., \& Buckley, P. C. (2014). Fathers' experiences with the special education system: The overlooked voice. Research and Practice for Persons with Severe Disabilities, 39(2), 119-135.

Patti, A. (2016). Back to the basics: Practical tips for IEP writing. Intervention in School and Clinic, 51(3), 151-156. doi:10.1177/1053451215585805 
Pizur-Barnekow, K., Patrick, T., Rhyner, P. M., Folk, L., \& Anderson, K. (2010). Readability levels of individualized family service plans. Physical \& Occupational Therapy in Pediatrics, 30 , $248-258$.

Ruble, L. A., McGrew, J., Dalrymple, N., \& Jung, L. A. (2010). Examining the quality of IEPs for young children with autism. Journal of Autism and Developmental Disorders, 40(12), 14591470. doi:10.1007/s10803-010-1003-1

Ryan, L. B., \& Rucker, C. N. (1991). The development and validation of a measure of special education teachers' attitudes toward the individualized educational program. Educational and Psychological Measurement, 51(4), 877-882. doi:10.1177/001316449105100408

Shelden, D. L., Angell, M. E., Stoner, J. B., \& Roseland, B. D. (2010). School principals' influence on trust: Perspectives of mothers of children with disabilities. The Journal of Educational Research, 103(3), 159-170. doi:10.1080/00220670903382921

Tisdell, E. J., Taylor, E. W., \& Forté, K. S. (2013). Community-based financial literacy education in a cultural context: A study of teacher beliefs and pedagogical practice. Adult Education Quarterly, 63(4), 338-356.

Tucker, V., \& Schwartz, I. (2013). Parents' perspectives of collaboration with school professionals: Barriers and facilitators to successful partnerships in planning for students with ASD. School Mental Health, 5(1), 3-14. doi:10.1007/s12310-012-9102-0

Turnbull, A., Turnbull, R., Erwin, E. J., Soodak, L. C., \& Shogren, K. A. (2015). Families, professionals, and exceptionality: Positive outcomes through partnerships and trust (6th ed.). Upper Saddle River, NJ: Merrill Prentice Hall.

Van Haren, B., \& Fiedler, C. R. (2008). Support and empower families of children with disabilities. Intervention in School and Clinic, 43(4), 231-235.

Westling, D. L. (2010). Teachers and challenging behavior: Knowledge, views, and practices. Remedial and Special Education, 31(1), 48-63. doi:10.1177/0741932508327466

Williams-Diehm, K. L., Brandes, J. A., Chesnut, P. W., \& Haring, K. A. (2014). Student and parent IEP collaboration: A comparison across school settings. Rural Special Education Quarterly, $33(1), 3-11$.

\section{Authors' Note}

Correspondence concerning this article should be addressed to Mariana Mereoiu. Email: mmereoi@bgsu.edu 